DOI: 10.36910/6775-2524-0560-2020-40-05

УДК: 004.93'1: 004.032.26

Загородній Олександр Володимирович, спеціаліст кафедра автоматизації та інтелектуальних інформаційних технологій

https://orcid.org/0000-0002-8649-1423

Вінницький національний технічний університет

\title{
ПРИНЦИПИ МЕДИЧНОЇ ДІАГНОСТИКИ ЗЛОЯКІСНОГО РАКУ ШКІРИ ЛЮДИНИ ЗА ДОПОМОГОЮ ШТУЧНИХ НЕЙРОННИХ МЕРЕЖ.
}

Загородній О. В. Принципи медичної діагностики злоякісного раку шкіри людини за допомогою штучних нейронних мереж. Наведено принципи медичної діагностики онкологічних захворювань шкіри людини за допомогою штучних нейронних мереж. Розкрито аспекти розвитку штучного інтелекту, які дозволяють створювати на базі біологічних підходів інтелектуальні системи в різних областях застосування. Охарактеризовано етапи онкологічної діагностики, які $\epsilon$ обов'язковими та мають фундаментальний вплив на подальше лікування пацієнта у разі діагностування злоякісного раку шкіри, результатом кожного з етапів $\epsilon$ клінічний діагноз, морфологічний діагноз та патоморфологічний діагноз. Окреслено поняття меланоми та особливості іï розвитку. Досліджено алгоритми автоматизованого комп'ютерного аналізу дерматологічних зображень, які забезпечують допомогу лікарям у постановці діагнозу та сприяють підвищенню точності діагностики. Розроблено структурну схему діагностування онкологічних захворювань шкіри людини за допомогою штучних нейронних мереж. В основі завдання диференціації патологій шкірних покривів людини лежить умовний поділ на 4 частини для вирішення завдань бінарної класифікації. Підкреслено, що навчання штучної нейронної мережі відбувається за допомогою наборів даних. Наголошується, що враховуючи завдання бінарної класифікації, у кожному напрямку застосування, наборам даних присвоюються мітки класу нуль та один, представлені у вигляді масиву. У статті розроблено детальний алгоритм, наведений у вигляді блок-схеми, здатний здійснювати постановку остаточного медичного діагнозу щодо захворювання шкіри на онкологічні патології за допомогою штучної нейронної мережі. Описаний алгоритм розроблений на основі штучних нейронних мереж, навчених вирішувати завдання бінарної класифікації. Результатом роботи штучної нейронної мережі є висновок приналежності вхідного значення до класів, на яких описана нейромережа проходила етап навчання.

Ключові слова: штучна нейронна мережа, інновації, механізм, діагностика, медицина, захворювання шкіри, злоякісна пухлина, онкологія, автоматизація.

Загородний А. В. Принципы медицинской диагностики злокачественного рака кожи человека с помощью искусственных нейронных сетей. Приведены принципы медицинской диагностики онкологических заболеваний кожи человека с помощью искусственных нейронных мереж.Розкрито аспекты развития искусственного интеллекта, позволяющие создавать на базе биологических подходов интеллектуальные системы в различных областях применения. Охарактеризованы этапы онкологической диагностики, которые являются обязательными и имеют фундаментальное влияние на дальнейшее лечение пациента в случае диагностирования злокачественного рака кожи, результатом каждого из этапов является клинический диагноз, морфологический диагноз и патоморфологический диагноз. Определены понятия меланомы и особенности еe развития. Исследовано алгоритмы автоматизированного компьютерного анализа дерматологических изображений, которые обеспечивают помощь врачам в постановке диагноза и способствует повышению точности диагностики. Разработана структурная схема диагностирования онкологических заболеваний кожи человека с помощью искусственных нейронных мереж.В основе задания дифференциации патологий кожных покровов человека лежит условное разделение на 4 части для решения задач бинарной класификации.Пидкреслено, что обучение искусственной нейронной сети происходит с помощью наборов данных. Отмечается, что учитывая задачи бинарной классификации, в каждом направлении применения, наборам данных присваиваются метки класса ноль и один, представленные в виде масиву.У статьи разработан детальный алгоритм, приведенный в виде блок-схемы, способен осуществлять постановку окончательного медицинского диагноза по заболеванию кожи на онкологические патологии с помощью искусственной нейронной сети. Описанный алгоритм разработан на основе искусственных нейронных сетей, обученных решать задачи бинарной классификации. Результатом работы искусственной нейронной сети вывод принадлежности входного значения в классы, на которых описана нейросеть проходила этап обучения.

Ключевые слова: искусственная нейронная сеть, инновации, механизм, диагностика, медицина, заболевания кожи, злокачественная опухоль, онкология, автоматизация.

Zahorodnii O. V. Principles of medical diagnostics of malignant human skin cancer using artificial neural networks. The principles of medical diagnostics of human skin cancer using artificial neural networks are presented. Aspects of the development of artificial intelligence that allow creating intelligent systems based on biological approaches in various fields of application are disclosed. The stages of oncological diagnostics are characterized, which are mandatory and have a fundamental impact on the further treatment of the patient in the case of diagnosis of malignant skin cancer, the result of each of the stages is a clinical diagnosis, morphological diagnosis and pathologic diagnosis. The concept of melanoma and its development features are outlined. The algorithms of automated computer analysis of dermatological images that provide assistance to doctors in making a diagnosis and contribute to improving the accuracy of diagnostics are studied. A block diagram for diagnosing human skin cancer using artificial neural networks has been developed. The problem of differentiation of human skin pathologies is based on a conditional division into 4 parts for solving binary classification problems. It is emphasized that the artificial neural network is trained using data sets. It is noted that given the problems of binary classification, in each direction of application, data sets are assigned labels of class zero and one, represented as an array. In the article, a detailed algorithm described in the form of a flowchart is developed that is able to make a final medical diagnosis of skin diseases and oncological pathologies using an artificial neural network. The described algorithm is based on artificial neural networks trained to solve binary classification problems. The result of 
the artificial neural network is the output of the membership of the input value of classes that describe the neural network passed the training stage.

Key words: artificial neural network, innovations, mechanism, diagnostics, medicine, skin diseases, malignant tumor, oncology, automation.

Вступ та постановка проблеми дослідження. В умовах сьогодення, зростає тенденція проектування систем штучного інтелекту на основі нейронних мереж, штучних імунних систем, еволюційного програмування та інших, біологічно інспірованих підходів. Це пов'язано з різними аспектами в розвитку штучного інтелекту. Перший полягає в здатності нейроінтелектуальних систем до навчання і самоорганізації, що дозволяє створювати на базі їх різні системи, що володіють властивістю адаптації до зовнішнього середовища. Другий аспект цієї проблеми характеризується здатністю нейроінтелектуальних систем після навчання узагальнювати і прогнозувати результати навчання. Таке узагальнення здійснюється шляхом інтеграції приватних даних, в результаті чого відбувається визначення закономірностей процесу. Третій аспект полягає в здатності таких систем вирішувати важко-формалізовані завдання, для яких не існує ефективного математичного алгоритму. Все це дозволяє створювати на базі біологічних підходів інтелектуальні системи в різних областях застосування. Такі інтелектуальні системи здатні до самоорганізації 3 метою адаптації до зовнішнього середовища.

Одним 3 найбільш затребуваних і перспективних напрямків впровадження розробок в даній області $\epsilon$ вирішення завдань медичної діагностики такого розповсюдженого захворювання як меланома. Перш за все, це обумовлено великим обсягом і складним характером аналізованих даних, результати яких клініцист не може повною мірою осмислити і врахувати в своїх висновках [1]. Як показує практика, традиційні медичні системи діагностики не знаходять широкого застосування в лікувальних установах, незважаючи на досить високий рівень використання комп'ютерної техніки. Це в значній мірі пов'язано з особливостями медико-біологічної інформації щодо наявності та прогресування меланоми на тілі людини. Традиційні системи потребують детального опрацювання математичних алгоритмів, за допомогою яких кожна така система діагностики повинна вирішувати завдання класифікації і робити необхідні висновки (наприклад, ставити діагноз). Велика кількість факторів, що надають прямий і непрямий вплив на кінцевий результат діагностики, ускладнює створення нових алгоритмів, а вже розроблені алгоритми не володіють необхідною точністю i прийнятним часом роботи [2]. Саме на основі цього, на сьогодні, перспективним напрямком $€$ застосування нейромережевих технологій (НMT) для вирішення завдань клінічної діагностики меланоми.

Аналіз останніх досліджень і публікацій. Застосування методів штучного інтелекту для виявлення клінічної картини широко застосовується в медичній діагностиці. Щороку у наукових виданнях з'являється понад пів тисячі академічних публікацій щодо застосування штучних нейронних мереж в медичній практиці діагностування різних видів захворювань [3]. Згідно опублікованій літературі, штучні нейронні мережі $\epsilon$ ефективним засобом для автоматичної діагностики захворювання і допомагають лікарю прийняти адекватне рішення, щодо стану пацієнта та подальших заходів лікування.

До питання розпізнавання змін властивостей об'єкта за зображеннями на основі штучних нейронних мереж детально підійшов І.В. Новосельцев [4]. Автором вирішена актуальна науковопрактична задача побудови нейромережевих методів розпізнавання і класифікації зміни властивостей зображень, які на відміну від існуючих, зменшують помилку розпізнавання і збільшують точність класифікації зображень в умовах апріорної $\mathrm{i}$ поточної невизначеності i наявності завад. У дисертаційній роботі вперше розроблено метод контролю зміни розмірів об'єкта за допомогою еталона 3 використанням властивостей перетворення подібності об'єктів, що дозволяє підвищити точність вимірювань.

М.I. Проценко, А.С. Васюра [5] розкрили застосування нелінійних систем передачі інформації в медицині. Досліджені фактори обробки інформації та формування діагнозу на основі отриманих даних.

Принципи застосування інформаційних технологій моніторингу та оцінки ефективності діагностики стану технічних і кардіосистем детально розглянула Т. М. Булана [6]. У практичній частині дисертаційного дослідження авторка пропонує алгоритм удосконаленої гібридної нейронної мережі та оптимізацію іiі параметрів. Даний підхід дозволив реалізувати механізми класифікації та кластеризації для підвищення точності кінцевих даних. 
Проте, питання розкриття дієвих механізмів застосування штучних нейронних мереж у межах медичної діагностики злоякісного раку шкіри людини залишається відкритим та потребує детального опрацювання.

\section{Постановка завдання.}

У статті необхідно розкрити принципи медичної діагностики злоякісного раку шкіри людини за допомогою штучних нейронних мереж.

\section{Виклад основного матеріалу дослідження.}

Онкологічна діагностика складається 3 трьох принципово важливих етапів: скринінг або рання діагностика (анамнез, неінвазія), як результат клінічний діагноз; морфологічний аналіз (гістологія, імуногістохімія, молекулярні дослідження), як результат морфологічний діагноз; патоморфологічний аналіз, як результат патоморфологічний діагноз. Недосконалість кожного 3 етапів впливає на остаточний діагноз та подальше лікування, саме тому точність $є$ пріоритетною складовою у медичній діагностиці.

Меланома являє собою злоякісну пухлину переважно шкірної локалізації, вона, на сьогоднішній день, є одним з найнебезпечніших видів онкологічних захворювань.

Меланома $є$ одним 3 типів раку серед всіх видів онкологічних захворювання, що найбільш швидко зростає кількісно, даний тип онкологічного захворювання здійснює найбільший внесок у смертність від усіх типів раку шкіри людини. Високий рівень смертності при захворюванні меланомою, як правило, пояснюється пізньою діагностикою захворювання. У той же час, при виявленні на ранніх стадіях, хірургічне лікування дає хороші прогностичні результати і може забезпечити практично $100 \%$ виживаності.

У боротьбі зі смертністю від меланоми на перший план виходить вторинна профілактика або превентивна медицина, яка у сучасному світі доволі розвинена та повсюдно пропагується засобами масової інформації. Своєчасні огляди, терапія і контроль поширення рецидивів є при регулярному самостійному або дерматологічному обстеженні знижує смертність пацієнтів на 63\% [7].

Сучасний розвиток технологій в області обробки зображень і машинного навчання дозволяє створювати системи на основі штучних нейронних мереж, що перевершують людину в задачах медичного діагностування раку шкіри пацієнта. Існують алгоритми автоматизованого комп'ютерного аналізу дерматологічних зображень, які дозволяють визначати межу, яскравість, діаметр і симетрію пігментації [8] i, тим самим, забезпечують допомогу лікарям для підвищення точності діагностики [9]. Останнім часом активно ведеться розробка систем, заснованих на технологіях штучного інтелекту, зокрема штучний нейронних мереж, дія яких направлена на можливість самостійного виявлення злоякісних утворень на ранній стадії [10]. Дослідження показують високий потенціал застосування нейромережевих технологій для діагностики новоутворень шкіри людини.

Діагностування онкологічних захворювань шкіри людини за допомогою штучних нейронних мереж відбувається у відповідності до структурної схеми наведеної на рисунку 1. 

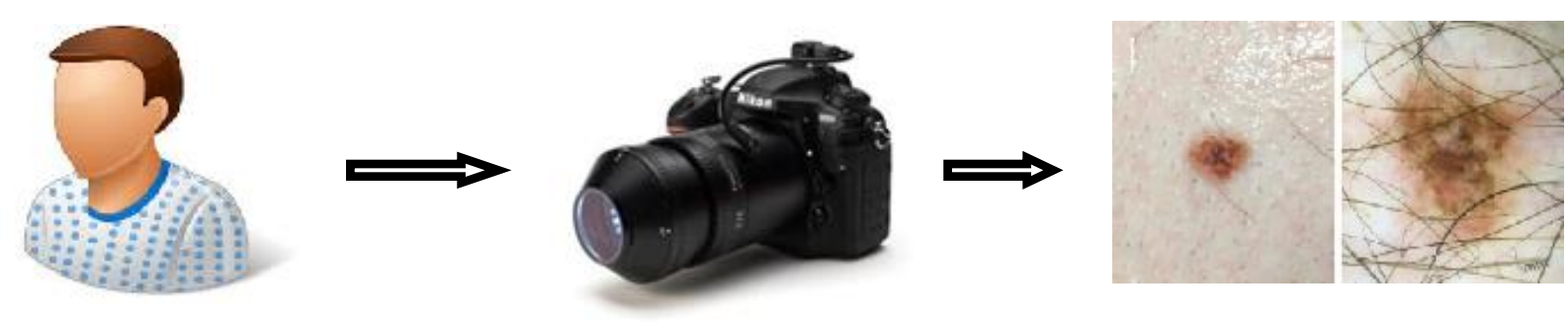

Пацієнт
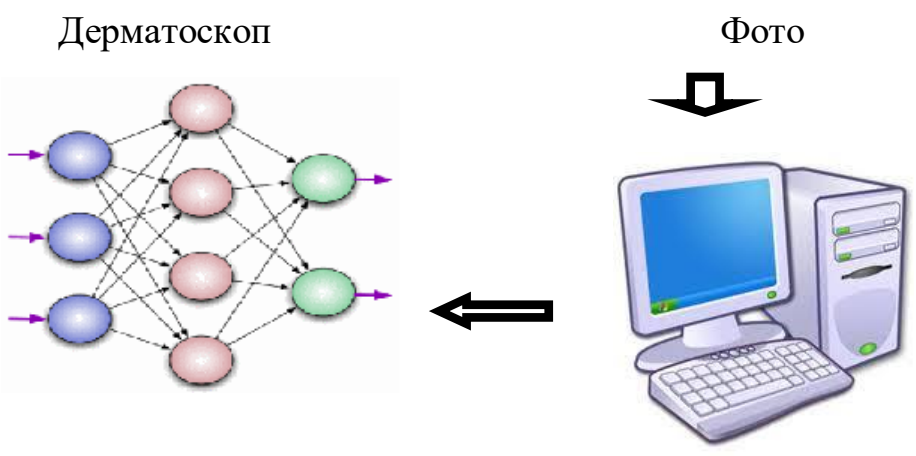

Результати медичної діагностики

\section{Штучна нейронна}

мережа

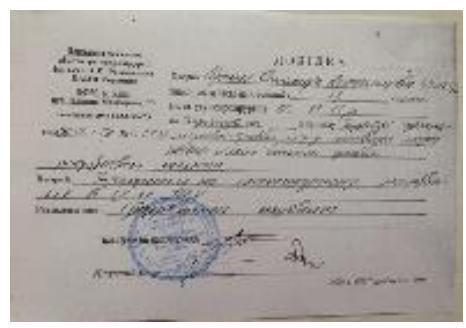

Результати

медичної

діагностики
Персональний комп'ютер

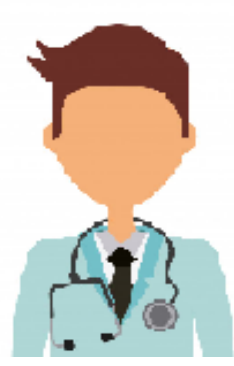

Лікар

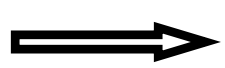

Рисунок 1 - Структурна схема медичної діагностики злоякісного раку шкіри людини за допомогою штучних нейронних мереж

* власна розробка автора

Формально, завдання диференціації патологій шкірних покривів людини поділено на 4 частини. Штучна нейронна мережа навчається для вирішення завдань бінарної класифікації:

1. Меланома / базаліома (м/б).

2. Меланома / невус (м/н).

3. Базаліома/невус (б/н).

4. Доброякісні / злоякісні пухлини (д/з). 


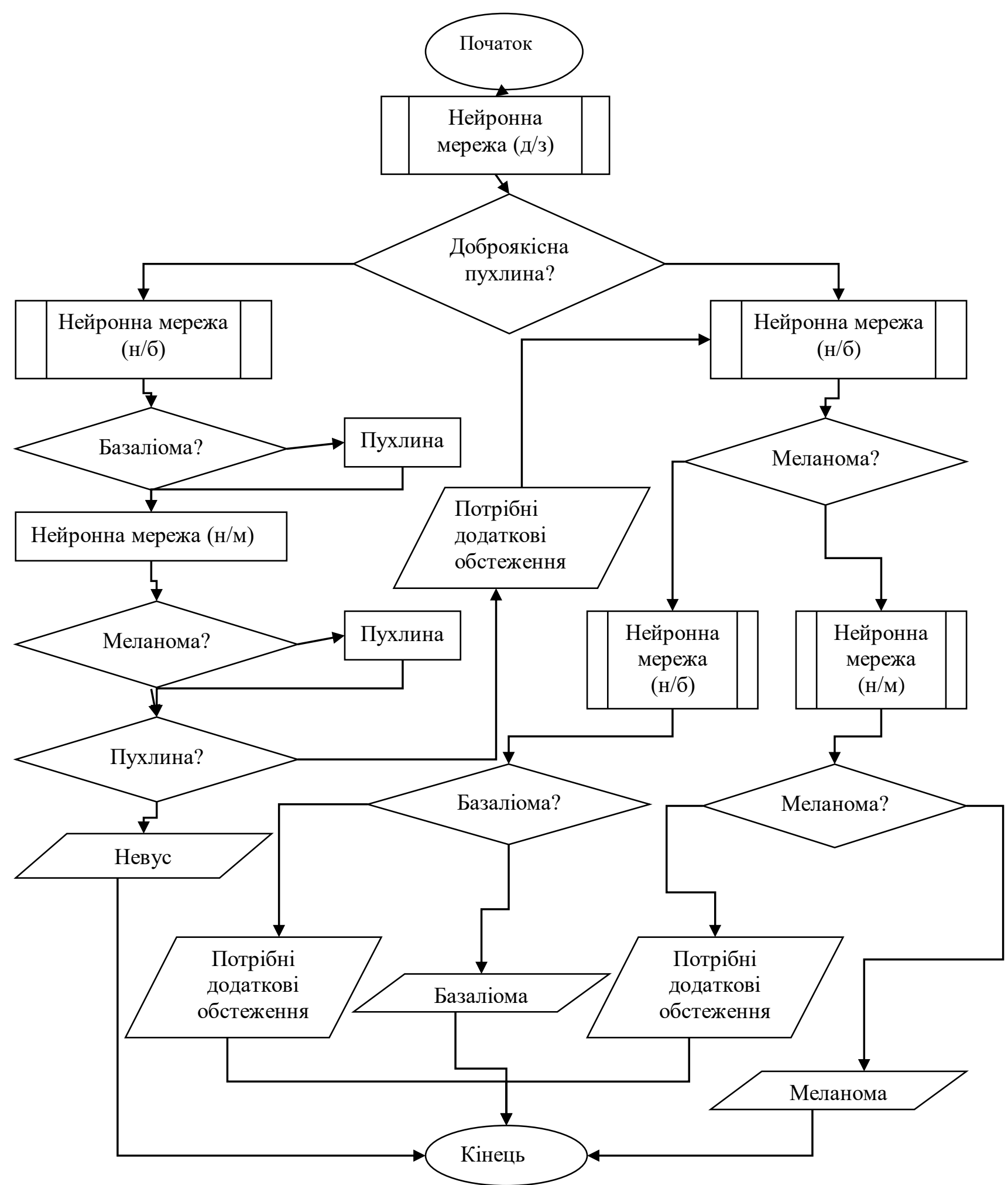

Рисунок 2 - Блок-схема алгоритму постановки остаточного медичного діагнозу щодо захворювання шкіри за допомогою нейронної мережі

Навчання штучної нейронної мережі відбувається за допомогою наборів даних (одним 3 найбільших архівів зображень шкірних новоутворень $€$ International Skin Imaging Collaboration (ISIC)), які складають вибірки необхідні для навчання нейронної мережі. Відповідно до завдання бінарної класифікації їм присвоюються мітки класу 0,1 , представлені у вигляді масиву.

На основі нейронних мереж, навчених вирішувати завдання бінарної класифікації розроблений алгоритм прийняття зваженого рішення щодо постановки остаточного медичного діагнозу.

Блок-схема алгоритму представлена на рисунку 2. 
На виході нейронна мережа надає імовірнісний висновок приналежності вхідного значення до класів, на яких вона навчалася.

Питання розробки алгоритму заснованого на імовірнісному висновку нейронних мереж, а так само поліпшення існуючого алгоритму є перспективним напрямком подальших досліджень.

Висновки.У ході дослідження визначено принципи медичної діагностики захворювань шкіри людини за допомогою штучних нейронних мереж. Використання інтелектуальних систем такого типу для діагностики шкірних захворювань пацієнта надасть істотну підтримку в постановці діагнозу як дерматологам, так і лікарям загальної практики.

Крім того, з впровадженням діагностичних систем заснованих на штучних нейронних мережах стане можливим застосування експертних систем підтримки прийняття рішень, а також засобів віддаленого консультування, що розширить спектр впровадження.

\section{Список бібліографічного опису}

1.Шевченко А.І. (ред.) (2019). Онкологія: підручник. Вінниця: Нова Книга. 512 с.

2.Доля, Ю. О., Григоренко, С. В., Щербатюк, Т. М., Вітюк, Н. В., Дика, А. П., Конькова, Т. В., \& Корчинський, О. Г. (2018). Клінічний випадок лікування раку шкіри носа. Оперувати чи опромінювати?, 26 (2), 124-125.

3.Бондар Г. В., Шевченко А. І., Галайчук І. Й. (2019). Онкологія: національний підручник для студентів медичних закладів вищої освіти. 2-ге вид., переробл. та допов Київ: Медицина. 518 с.

4.Новосельцев, I. В. (2019). Методи та засоби розпізнавання змін властивостей об’єкта за зображенням на основі штучних нейронних мереж: дис.на здобуття наукового ступеню канд. техн. наук : 05.13.23 “Системи та засоби штучного інтелекту" / М-во освіти і науки України, Харків. нац. ун-т радіоелектроніки. Харків. 200 с.

5.Проценко М.I., Васюра А.С. (2020). Нейронні мережі в медицині. Вінницький національний технічний університет, URL: http://ir.lib.vntu.edu.ua/bitstream/handle/123456789/29316/8908.pdf?sequence=3 (дата звернення: 17.03.2020)

6.Булана Т.М. (2018). Інформаційні технології моніторингу й оцінки ефективності діагностування стану технічних та кардіосистем : дис. канд. техн. наук : 05.13.06 / Дніпров. нац. ун-т ім. Олеся Гончара. Дніпро165 с.

7.Меланома є основною причиною смерті від раку шкіри (2020) / Центр громадського здоров’я MO3 України. URL: https://www.phc.org.ua/news/melanoma-e-osnovnoyu-prichinoyu-smerti-vid-raku-shkiri. (дата звернення: 17.03.2020)

8.Що треба знати про меланому (2020) / Міністерство охорони здоров'я України. URL: https://moz.gov.ua/article/health/scho-treba-znati-pro-melanomu. (дата звернення: 17.03.2020)

9.Булана Т., Молодець Б. (2020). Аналіз існуючих варіантів класифікації хворих на серцево-судинні захворювання за допомогою нейронних мереж. «Системні технологіï» «System technologies», 5 (130), 71-78.

10. Чумаченко O.I. (2019). Структурно-параметричний синтез гібридних нейронних мереж: дис. канд. техн. наук : 05.13.23 / Національний технічний університет України «Київський політехнічний інститут імені Ігоря Сікорського». Київ, 662 с.

\section{References}

1. Shevchenko A.I. (ed.) (2019). Oncology: a textbook. Vinnytsia: New Book. 512 s.

2. Dolya, Yu. O., Grigorenko, SV, Shcherbatyuk, TM, Vityuk, NV, Dika, AP, Konkova, TV, \& Korchinsky, OG . (2018). Clinical case of treatment of nasal skin cancer. Operate or irradiate? , 26 (2), 124-125.

3. Bondar G.V., Shevchenko A.I., Galaychuk I.Y. (2019). Oncology: a national textbook for students of medical institutions of higher education. 2nd ed., Reworked. and additional Kyiv: Medicine. $518 \mathrm{~s}$.

4. Novoseltsev, I.V.(2019). Methods and means of recognizing changes in the properties of an object by image based on artificial neural networks: dissertation for the degree of Cand. tech. Sciences: 05.13.23 "Systems and means of artificial intelligence" / Ministry of Education and Science of Ukraine, Kharkiv. nat. University of Radio Electronics. Kharkiv. 200 s.

5. Protsenko M.I., Vasyura A.S.(2020). Neural networks in medicine. Vinnytsia National Technical University, URL: http://ir.lib.vntu.edu.ua/bitstream/handle/123456789/29316/8908.pdf?sequence=3 (access date: 17.03.2020)

6. Bulana T.M.(2018). Information technologies of monitoring and an estimation of efficiency of diagnosing of a condition of technical and cardiac systems: dis. Cand. tech. Sciences: 05.13.06 / Dniprov. nat. Univ. Oles Honchar. Dnipro165 s.

7. Melanoma is the leading cause of death from skin cancer (2020) / Public Health Center of the Ministry of Health of Ukraine. URL: https://www.phc.org.ua/news/melanoma-e-osnovnoyu-prichinoyu-smerti-vid-raku-shkiri. (appeal date: 17.03.2020)

8. What you need to know about melanoma (2020) / Ministry of Health of Ukraine. URL: https://moz.gov.ua/article/health/scho-treba-znati-pro-melanomu. (appeal date: 17.03.2020)

9. Bulana T., Well done B. (2020). Analysis of existing options for classification of patients with cardiovascular diseases using neural networks. "System technologies", "System technologies", 5 (130), 71-78.

10. Chumachenko O.I. (2019). Structural-parametric synthesis of hybrid neural networks: dis. Cand. tech. Sciences: 05.13.23 / National Technical University of Ukraine "Kyiv Polytechnic Institute named after Igor Sikorsky". Kyiv, 662 p. 